\title{
LAS DOS EDICIONES DE LA "TRAGEDIA POLICIANA" Y LA ACTUACIÓN DE LUIS HURTADO DE TOLEDO
}

\author{
Luis Mariano Esteban \\ Madrid
}

A mi maestro Víctor Infantes

En 1547, en las prensas de Pedro de Castro, aparece la primera edición de la Tragedia Policiana. ${ }^{1}$ Se trata de una obra en $4^{\circ}$, letra gótica, con lxxx folios numerados, aunque en realidad son setenta y ocho pues falta el folio ii, numerado erróneamente, y el folio 1 . Signaturas aiij +1 (aunque falta la aij) + bv -3 lij +1 . La descripción de la edición es la siguiente:

[Orla de cuatro piezas (en la de abajo, en el centro, aparece un escudo con la flor de lis) con motivos vegetales y humanos enmarcando el título ][corazón] Tragedia $\mathrm{Po}=/$ liciana.En la qual se tractanlos muy/desdichados amores de Poli=/ciano yPhilomena.Exe/cutados porindustria/de la diabolica/vieja Clau/dina/Madre deParme/no y maestra de/Celestina. [El subrayado aparece en rojo en la edición. Debajo

1 A. Palau y Dulcet, Manual del librero hispanoanicricano, t.24 (Barcelona: Librería Palau, 1962), p. 20. Este impresor, que inició su actividad en Salamanca en 1538 y posteriormente se trasladó a Medina del Campo y de cuyas prensas salieron obras como las de Boscán (1544), tenía como marca tipográfica la flor de lis con o sin sus iniciales, como aparece en la Tragedia Policiana en el taco inferior de la orla, y suele ser frecuente que aparezca este sello aunque no aparezca su nombre en el colofón, como igualmente ocurre en nuestra obra. Sobre estas cuestiones puede verse el trabajo de C. Pérez Pastor, La imprenta en Medina del Campo (Madrid, 1895), 462-483. 
del título aparece un grabado con un caballero entregrando una flor a una dama.]

PORTADA, a la vuelta:

- [calderón] El Alctor (sic) a vn ainigo suyjo. [en prosa] fo.ij (sic). SI la soledad de mi vida, muy noble señor/no oniera faborescido

- [calderón] $A$ los enamorados. [cuatro octavas acrósticas donde se lee: $E L L$ BACHELLER SEBASTIAN FERNANDEz (sic), no interviniendo las iniciales de los tres últimos versos, y terminados con $A$ men.] fo. ijr-iijv

- [calderón] El Actor.al Lector. [en prosa y terminado en corazón] Uale [corazón] fo. iijr-iiijr.

TEXTO, que corre desde el folio iiijv al lxxxv [se inicia con el argumento del primer acto y a continuación se reseñan los nombres de los personajes que intervienen en la obra. Cada acto va encabezado por su argumento y un grabado en el que aparecen diversas figuras que representan a los personajes que intervienen en dicho acto con indicación de sus nombres y en ocasiones (actos primero, décimo y decimosexto) enmarcados entre edificios [en el acto décimo aparece el edificio invertido en todos los ejemplares], o por un árbol (acto decimoquinto). Los veintinueve actos se numeran correlativamente, aunque aparece una errata en el acto $X X$, que se numera como XXII].

COLOFÓN: [corazón] Acabose esta tragedia/Policiana a.xx.dinsdelmesde Nouiebre a costa/deDiego lopez librero vezino deToledo./Año de nra Redepcion demil/y quiniento sy quaren/ta y siete.: [corazón][calderón] Nihil in humanis rebus perfectum. ejemplares:

De esta edición tenemos, a lo que se me alcanza, los siguientes

1. Biblioteca Nacional de Madrid, utilizado para la descripción, signatura R.26.620

2. Biblioteca PAN, en Gdansk, signatura DK $47648^{\circ}$, citado y descrito de modo incompleto por Anna Okonska. ${ }^{2}$

${ }^{2}$ A. Okonska, "Análisis comparativo entre la Tragicomedia de Callsto y Melibca de Fernando de Rojas y la Tragedia Policiana de Sebastián Fernández" (Tesis, Univ. de Roma, 1979), pp. 3-5. 
3. Universidad de Salzburgo, Institut Romanistik, descrito por Mörtinger. ${ }^{3}$

4. Museo Británico, con la signatura C.125.b.2.,en cuya cubierta aparecen las armas de Isabel, la mujer de Felipe IV (Môrtinger 8).

5. La edición realizada por Menéndez y Pelayo en Orígenes de la novela, t.3, Madrid: NBAE 14, 1910, siguiendo el ejemplar de la Biblioteca Nacional de Madrid.

6. Mi edición publicada como tesis doctoral por la Universidad Complutense de Madrid, 1992.

De Sebastián Fernández carecemos de cualquier noticia biográfica fidedigna. Menéndez y Pelayo, apoyándose en las palabras de Philomena al encontrar el cadáver de Policiano, se refirió a Sebastián Fernández como un autor que "debía de estar recién salido de las aulas con la leche de la retórica en los labios." autor como clérigo, ${ }^{5}$ suposición a la que se suma Mörtinger (18), mientras que Okonska señala su posible relación con el mundo de los juristas o del clero (3). En cualquier caso, estamos ante meras hipótesis, ya que ni de las piezas preliminares ni del aparato erudito que aparece en el texto puede extraerse conclusión alguna fiable. Por otra parte, el hecho de que en el texto dirigido Al Lector el autor declare que la creación literaria es ajena a su profesión bien puede entenderse como un mecanismo de relación cíclica (afirmación similar encontramos en Celestina y en la Tragicomedia de Lisandro y Roselia) amén de como evidente recurso de captatio benevolentine, frecuente en la tradición literaria y especialmente en la comedia humanística. ${ }^{6}$

Un año después, también en Toledo, aparece la segunda edición en las prensas de Fernando de Santa Catalina, impresor con quien finaliza

${ }^{3}$ Gertrud Mörtinger-Grohmann, "Tragedia Policiana von Sebastián Fernández. Untersuchung einer der spanischen imitationem der Celestina" (Tesis, Univ. Salzburg, 1979), 6-7.

4 M. Menéndez y Pelayo, Orígenes de la nozela, t.3 (Madrid: NBAE, 14, 1910), p. cxxlix.

${ }^{5}$ M. Bataillon, La Célestine sclon Fcrnando de Rujas (París: Didier, 1961), p. 111.

${ }^{6}$ D. W. McPheeters, "Pronza y La Celestina," en Estudios humanisticos sobre 'La Celestina' (Potomac, Maryland: Scripta Humanistica, 1985), p. 77. 
el dominio de la letra gótica en favor de la letra redonda ${ }^{7}$ y de cuyas prensas saldrá otra obra integrante del ciclo celestinesco: la Tercera parte de la tragicomedia de Celestina, de Gaspar Gómez. Es una edición en 4\%, letra gótica, sin foliar (tiene 72 folios). Signaturas Aiij $+5+$ Biij -Jiiij + 4. La descripción de esta edición es la siguiente:

[Orla de cuatro piezas, la de arriba y la de abajo con motivos vegetales y humanos, enmarcando un grabado que representa la casa de Philomena, donde se ve a la dama, a su padre $y$, probablemente, a su criada. A la puerta aparece llamando la alcahueta. En la calle se ve a un paje llevando un caballo de la brida. Debajo el título][corazón] Tragedia muy sentida y/graciosa llamada la madre Claudina Madre/de Parmeno y maestra de Celestina.En la/qual por elegante prosa y excelentes di=/chos se trata los desdichados amo=/res de vn Caunallero llamado/Policiano y vna dama/Philomena cuya/hystoria dara testimonio de su delicado estilo. [El subrayado aparece en rojo en la edición. $]^{8}$

PORTADA, a la vuelta:

- [calderón] El Actor a vn amigo suyo. [en prosa] SI la soledad de mi vida/imuy noble sefior/no ouiera fauorescido

- [calderón] $A$ los enamorados. [cuatro octavas acrósticas similares a las de la editio princeps, pero donde se omite Amen.]

- [calderón] El Actor al Lector. [en prosa y terminado en [calderón] Uale..

TEXTO [se inicia con la relación de los personajes que intervienen en la obra. A continuación se desarrollan los veintinueve actos iniciados por su argumento y un grabado con los personajes que intervienen y sus nombres. Sólo en los actos primero, décimo y decimosexto aparece un edificio enmarcando las figuras. Los actos se numeran correlativamente, repitiéndose la errata de la editio princeps].

- En la vuelta del penúltimo folio [calderón] Luis Hurtado al Lector.[tres octavas].

COLOFÓN: [calderón] A honor y gloria dela sanctissi/ma Trinidad: y concepcion dela gloriosa virgen santa/Maria:Acabose esta presente obra en la

7 J. Vega González, La imprenta en Toledo. Estanupas del Renacimiento (Toledo: Instituto Provincial de Investigaciones y Estudios Toledanos, 1983), pp. 55-56. Se. citará en adelante por Vega y página.

${ }^{8}$ El grabado de esta segunda edición es idéntico al que aparece en la Comcdia Selvagia, obra también perteneciente a este ciclo, lo que se explica porque su impresor, Ioan Ferrer, heredó la imprenta de Santa Catalina. 
Impe=/rial cibdad de Toledo en casa de Fernando/de santa Cathalina que santa gloria aya:/al primero dia del mes de Março./Afo del nascimiento de nule=/stro Seftor lesu Chri=/sto de mil y quinien=/tosy quinretn/y ocho/años./( $\therefore)$.

De esta edición tengo noticia de los siguientes ejemplares:

1. British Library de Londres, signatura B.20.c.21;

2. Biblioteca Nacional de Viena, signatura 622223-B. Es el ejemplar sobre el que llamó la atención F. Wolf en su tratado titulado Sobre una colección de Romanzes volantes espafoles hallada en la Biblioteca de la Universidad de Praga (Viena 1850) y posteriormente en un trabajo sobre La Danza de la Muerte titulado "Ein spanisches Frohnleichnamspiel von Totentanz. Nacheinem alten Druck weider herausgegeben," en Sitzungherichten der Wiener Akademie der wissenschraften 8 (1852):114-150. Este trabajo fue traducido por Julián Sanz del Río en su Colección de documentos inéditos para la Historia de Espana 22 (1853):509-562. A este ejemplar le falta la portada y el primer folio, pero contiene las octavas de Hurtado y el colofón.

3. Biblioteca Real de Corte y Gobierno de Munich incluido en un tomo en $4^{\circ}$ (P.O. hisp. $4^{\circ}, 29$ ex electorali bibliotheca sereniss. utriusque Bavariae Ducum) junto con otra serie de obras dramáticas del siglo XVI, entre ellas la Comedia Florinen, citado por Wolf en el trabajo antes mencionado.

4. Bibliothéque de l'Arsenal, París, en un volumen con el título de TRAGEDIA POLICIANA/LUIS HURTADO/DE TOLEDO, que contiene seis obras más. La signatura es 12261.BL."

Esta segunda edición, junto al cambio de las estampas - imputable al impresor - presenta una serie de diferencias respecto a la princeps que bien podemos imputar a Luis Hurtado: el cambio del título, el importante cuerpo de variantes y la adición en la vuelta del penúltimo folio de tres octavas dirigidas al lector.

Por lo que respecta al cambio de estampación, éste se manifiesta en la portada, las letras capitulares y las estampas de los personajes que se incorporan al inicio de cada acto. Siguiendo a Jesusa Vega, podemos clasificar estas estampas en decorativas, informativas y de complemento, según la función predominante que cumplan en relación con el texto (Vega 58-59). Por lo que respecta a las portadas, en ambas ediciones nos

${ }^{9}$ Este ejemplar fue descubierto y descrito por C. H. Heaton en "A Volume of Rare Sixteenth Century Spanish Dramatic Works," Romanic Review 18 (1972): 339. 345. 
hallamos ante estampas del tipo decorativas-informativas, que junto con la función de adorno tienen un significado relacionado con el texto (Vega 60). En cuanto a las letras capitales, en ambas ediciones se trata de estampas decorativas que incorporan elementos vegetales o animales, niños, monstruos, etc.; son cuadradas, si bien en la segunda edición considerablemente más grandes y sobre fondo blanco, mostrando el proceso evolutivo que entre 1500-1550 se produce con el progresivo abandono del fondo negro, $y$, asimismo, en esta segunda edición hallamos ejemplos de letras iniciales en negro sobre fondo blanco, lo que no es usual en este período (Vega 59). Por último, en cuanto a las estampas complemento del texto, aunque distintas en las dos ediciones, en ambas representan a los personajes que intervienen en el acto con sus nombres y tienen la función, como J. R. Thomé señala para las de Celestina, de "precisar el vestuario, ciertas actitudes de los personajes y de ayudar así al lector a animar a éstos a través de la peripecia de la intriga" (Vega 72).

Centrándonos en la figura e intervención de Luis Hurtado de Toledo, la incorporación de las octavas finales llevó a de la Barrera, siguiendo a F. Wolf, a aludir a Hurtado como autor de la Tragedia Policiana. ${ }^{10}$ Respecto a esta cuestión, existe una amplia controversia relacionada con la identidad del personaje.

Lo único que parece indiscutible por los estudiosos es que Luis Hurtado fue rector de la parroquia de San Vicente, en Toledo, y también parece admitirse por todos que mantuvo una relación laboral como corrector con el impresor Fernando de Santa Catalina (Vega 55). ${ }^{11}$ Hijo de Juan Sánchez de San Pedro y de Leonor de la Fuente Hurtado, Luis Hurtado sucedió como rector de la iglesia de San Vicente al bachiller Pedro de Vega, estampando su primera firma como rector y cura propio de dicha iglesia el lunes 4 de febrero de 1544 para certificar el bautismo de un hijo de Pedro de la Torre y María Ortiz. ${ }^{12}$ Asimismo, mantuvo

${ }^{10} \mathrm{C}$. A. de la Barrera, Catálogo bibliográfico y biográfico del teatro antiguo español, desde sus orígenes hasta mediados del siglo XVIII (Madrid: Rivadeneyra, 1977), p. 190.

${ }^{11}$ Vega, siguiendo el colofón del Libro de cirugía, de Juan de Vigo, señala que Fernando de Santa Catalina había muerto el quince de julio de 1548. Sin embargo, su muerte, atendiendo al colofón de la Tragedia Policiana, es anterior a marzo de ese mismo año.

12 Antonio Blanco Sánchez, Entre fray Luis y Quezuedo. En lusca de Francisco de la Torre (Salamanca: Gráficas Cervantes, 1982), p. 227, n2. 
una estrecha relación con Luis de Vargas, de quien probablemente fue preceptor. ${ }^{13}$ Lo demás, desde la fecha de su nacimiento [en torno a 1530, como lo defienden de la Barrera (188 y 190) y García Soriano, ${ }^{14}$ en torno a 1510, como lo señala Rodríguez-Moñino, ${ }^{15}$ o, quizá con más acierto, en 1523, como lo muestra Antonio Blanco Sánchez ${ }^{16}$ ] a su participación en el Palmerin de Inglaterra ${ }^{17}$ y en la Tragedia Policiana aparecen como cuestiones controvertidas. Esta controversia se acentúa aún más con la tesis de Mary E. Greco, quien señala que sólo en aquellas obras en donde figura de Toledo se trata del Luis Hurtado párroco de San Vicente, mientras que en donde figure exclusivamente Luis Hurtado, como en la Tragedia Policiana, se trata de otra persona. ${ }^{18}$

${ }^{13}$ Abraham Madroñal Durán, "Don Luis de Vargas (1566-1591?), creador del Romancero Nuevo," Encuentros (Anuario de poemas, ponencias y comunicaciones de la Academia Ibernamericana de Poesía) 1 (1993), pp. 140ss. Este mismo autor, a quien agradezco algunas pistas en la búsqueda de Luis Hurtado, me anuncia que está preparando una edición sobre el Teatro pastoril.

${ }^{14}$ Justo García Soriano, "El Teatro de Colegio en España. Noticia y examen de algunas de sus obras," Boletín de la Real Academia Española 14 (1927): p. 241.

${ }^{15}$ A. Rodríguez-Moñino, Prólogo a las Cortes de Casto Amor y Cortes de la Muerte (Valencia: Andrés Ortega del Álamo, 1963), 31-33.

${ }^{16}$ Blanco Sánchez, 228. Este autor señala el 15 de marzo de 1590 como fecha de la muerte de Luis Hurtado (227).

${ }^{17}$ Rodríguez-Moñino, p. 11, alude a Luis Hurtado en relación con esta obra como traductor o simplemente como corrector. Por su parte, Blanco Sánchez vuelve sobre la posible autoría de Hurtado al quedar desmontado con la fecha de nacimiento que él propone el argumento contra dicha autoría de Hurtado atendiendo a su edad.

${ }^{18}$ Mary E.Greco, "Luis Hurtado de Toledo. A Biographical-Critical Study and an Edition of his Trescicntas en defensa de illustres mugeres,". (Tesis, Univ. of California-Berkeley, 1977), p. 93. El planteamiento de esta autora es bastante endeble pues si observamos textos como las Cortes d'casto amor y cortes d'la muerte o Las Trescientas, indistintamente nos encontramos con de Toledo o su supresión. Es más, en la Historia del golorioso martir Sant Vicente en octava rima del toledano Luis de la Cruz (1585), aparece un soneto intitulado LUYS HVRTADO ANCIANO PASTOR DEL MARTIR, AL SANTO Y AL AUTHOR, en donde, como vemos, no aparece de Toledo, pero es indudable que se trata del cura de San Vicente, de quien Luis Hurtado se denomina pastor. 
Los defensores de la autoría de Luis Hurtado en la Tragedia Policiana se apoyan en que en las octavas se lee: " $Y$ si su autor se haze callado/es por el vulgo tan falto de ciencias./ (...) /y si algun error hallares mirando/Supla mi falta tu gran discrecion/pues yerra la mano y no el coraçon."

Frente a éstos, Menéndez y Pelayo (ccxliv) señaló que "se haze callado" no podía referirse a Hurtado, quien al inicio de las octavas habia situado su nombre, y que los "errores" debían entenderse como "erratas tipográficas," de modo que Luis Hurtado era "un mero corrector de imprenta" y ni siquiera un continuador o remendador, como en múltiples ocasiones lo fue, "puesto que el texto de la segunda edición es idéntico al de la primera."

Comparto con Menéndez y Pelayo su afirmación de la incongruencia que supone que Hurtado aluda a sí mismo como "autor callado" cuando ha dispuesto su nombre encabezando las octavas. En mi opinión, es evidente que se refiere a Sebastián Fernández, quien sí ocultó su nombre a través de los versos acrósticos iniciales dedicados $A$ los enamorados, aunque para los lectores familiarizados con el ciclo celestinesco era una ocultación relativa, pues tenian el precedente de Celestina y de la Tragicomedia de Lisandro y Roselia, de modo que el acróstico sería, en palabras de Genette, un elemento más de paratextualidad" ${ }^{19}$ que ahondaría en la relación de la obra con Celestina.

Por otro lado, estas octavas de Hurtado bien podrían recordar al lector aquellas de Proaza y las aparecidas en la Tragicornedia de Lisandro y Roselia en las que se llamaba la atención de los lectores sobre la forma de descubrir el nombre del autor. Asi pues, aunque las octavas de Hurtado tienen considerables diferencias con respecto a los dos casos citados, me parece evidente que los lectores de la Tragedia Policiann, por similitud, se sentirían tentados a releer los versos iniciales, descubriendo así el nombre del autor.

En abundamiento de lo que acabo de señalar quizá no esté de más volver detenidamente sobre los dos versos más controvertidos de Hurtado: "y si su autor se haze callado/es por el vulgo tan falto de ciencins." Hurtado utiliza la preposición por en su función más genuina: expresar

${ }^{19}$ G. Genette, Palimpsestos. La literatura en scgundo grado (Madrid: Taurus, 1989), p. 11. 
la causa. ${ }^{20}$ De acuerdo con esto, Hurtado transmitiría a los lectores que si el autor "se haze callado" es debido al vulgo "fnlto de ciencias." Es decir, Sebastián Fernández, profesional de otra actividad, intenta pasar desapercibido para un vulgo que puede interpretar erróneamente la obra quedándose, "por su falta de ciencias," con "lo maio" y no "notando/lo prouechoso." En definitiva, el autor se oculta porque teme que el vulgo no entienda la ejemplaridad que se oculta debajo de los placeres amorosos descritos, ejemplaridad a la que alude en las octavas dedicadas $A$ los enamorados. Entendidos así estos versos, se reafirma la tesis de que Hurtado no es el autor de la obra.

Frente a esto, los errores a los que alude Hurtado y por los que pide benevolencia son los cometidos por él como corrector, de ahí que mientras para aludir al autor de la obra dice "si su autor se haze callado," I para referirse a los errores, sin duda tipográficos, utiliza el posesivo de primera persona: "Supla mi falta."

Por último, los defensores de la autoría de Luis Hurtado no explican cómo encajar dicha autoría con el mantenimiento del acróstico inicial. Considero obvio que si Luis Hurtado fuese el autor de la obra, no habría mantenido los acrósticos iniciales en donde se señalaba a otro como autor, máxime si tenemos en cuenta que la obra se incluía dentro de un ciclo de excelente éxito editorial.

En conclusión, Luis Hurtado nos presenta en la Tragedia Policiana dos de sus actividades más usuales: autor que incorpora textos propios en obras ajenas y corrector de imprenta. Respecto a lo primero, recordemos que Luis Hurtado realizó prólogos a distintas obras como al Hospital de galanes, y que incorporó un soneto en la traducción del Orlando Furioso realizada por Jerónimo de Urrea y en la Historia de las hazanas y hechos del inuencible Bernardo del Carpio, de Agustín Alonso, por citar unos ejemplos (Rodríguez Moñino 16, 25 y 26).

Respecto al papel de Hurtado como corrector, conviene anotar previamente la importante función que los correctores tenían en la época. Junto al Corrector general nombrado por el Consejo de la Cámara, todas

${ }^{20}$ Así lo señala ya Antonio de Nebrija, Gramática de la Lengua castellana, edición y estudio de Antonio Quilis, $3^{\mathrm{a}} \mathrm{ed}$., (Madrid: Ed. Centro de Estudios Ramón Areces, 1990), p. 208. 
las imprentas tienen correctores propios, ${ }^{21}$ de cuya importancia da buena cuenta el que en la escritura del contrato editorial se reseñaban, entre otras cuestiones, las obligaciones del corrector, ${ }^{22}$ obligaciones que no se limitaban a revisar la puntuación y la ortografía, sino que también estaban encargados de realizar la colación cuando tenían ante sí diversos originales. ${ }^{23}$ Además, todas aquellas ediciones realizadas sin la especial vigilancia de su autor, que eran las más pues los autores solían vender el Privilegio a los libreros, con lo que se desentendian de la edición, ${ }^{24}$ se exponían a considerables cambios, supresiones, alteraciones estructurales, etc. ${ }^{25}$ en definitiva, quedaban en manos de editores y correctores que añadian y suprimian a su antojo, como lo prueban, sin ir más lejos, las palabras finales del Prólogo de Celestina, o las del propio Hurtado en la Comedia de Preteo y Tibaldo llamada disputa y remedio de amor del Comendador Perálvarez de Ayllón, señalando que añadió "lo que a mi parescer senti que faltaua" al haber fallecido su autor (Rodríguez Moñino 14). Ahondando en la figura del corrector y en su importancia en la elaboración final del libro, conviene anotar cómo el impresor René Rabut y el tirador Diego de Cristóbal de Montoya insistian en los conocimientos que de ortografía y de las lenguas que se imprimían habían de tener los correctores ${ }^{26}$ Es más, estos dos mismos personajes se quejan de la falta de correctores en Granada, lo que redunda en abundantes errores en las impresiones. ${ }^{27}$

De las palabras de Hurtado en la obra de Perálvarez de Ayllón entroncando con la actividad de los correctores en general podemos entresacar que el corrector Luis Hurtado se siente facultado para participar en una obra ajena sin ocultar en ningún momento que la

n Agustín G. de Amezúa y Mayo, Cómo se hacía un libro en nuestro Siglo de Oro (Madrid: Magisterio Español, 1946), p. 33.

${ }^{22}$ Ibid, 28.

${ }^{23}$ McPheeters, "Proaza y La Celestina," p. 74.

24 Amezúa, 32.

${ }^{25}$ Alberto Blecua, Manual de crítica textual (Madrid: Castalia, 1983), p. 189.

${ }^{26}$ Ver J. Martinez Ruiz, "Visita a las imprentas granadinas de Antonio de Nebrija, Hugo de Mena y René Rabut en el año 1573," Revista de Dialectología y Tradiciones Populares 24 (1968), p. 81.

${ }^{2}$ Ibid, 85-86. 
misma no le pertenece, lo que encaja perfectamente con su actuación en la obra que nos ocupa.

Sentadas estas cuestiones, la intervención de Luis Hurtado como corrector en la Tragedia Policiana se centra en el cambio de título, corrección ortográfica, supresiones y adiciones. El título presenta una serie de elementos muy a tener en cuenta. Por un lado la denominación de tragedia, ya que es la única obra del ciclo celestinesco que aparece con esta denominación. Para Díez Borque, la obra se incluiría dentro de los "intentos de tragedia" en el siglo XVI junto con obras como la Tragedia Josefina, de M. de Carvajal, o la Tragedia Seraphina, de Alonso de Vega. ${ }^{28}$ Sin embargo, dicha denominación no ha de entenderse de acuerdo a la significación y características clásicas tal y como, por ejemplo, las describe Pinciano en su Filosofia antigua poética (Valladolid, 1596), sino bajo un influjo de Celestina, en cuyo Prólogo se concibe tragedia como aquella que "acabava en tristeza" (81). ${ }^{29}$ En definitiva, estamos ante una denominación extrateatral que remite a una concepción luctuosa de la trama. ${ }^{30}$

Ahora bien, mientras que la editio princeps se intitula por el nombre de uno de los enamorados - práctica común a todos los autores del ciclo celestinesco que, si bien no era usual en el teatro clásico, sí lo era en la tradición de la novela bizantina, género con el que Celestina y el conjunto de sus continuaciones tiene puntos en común, ${ }^{31}$ añadiéndose el nombre de la alcahueta y su relación con personajes de Celestina como Pármeno y la propia Celestina como incuestionable mecanismo de relación cíclica, ${ }^{32}$ en la segunda edición se antepone como título el nombre de la alcahueta, en lo que hemos de ver un clarísimo influjo del proceso de transmutación que había sufrido el título del modelo: Ordóñez intitula Celestina a su traducción de la Tragicomedia de Calisto y

${ }^{28}$ J. M. Díez Borque, Los géneros dramáticos en el siglo XVI (El tcatro hasta Lope de Vega) (Madrid: Taurus, 1987), p. 114.

${ }^{20}$ Cito por la ed. de D. S. Severin (Madrid: Cátedra, 1988).

${ }^{30}$ Diez-Borque, p. 76.

${ }^{31}$ J. R. Stamm, La estructura de La Colestina. Una lectura analitica (Salamanca: Univ, de Salamanca, 1988), p. 15.

${ }^{32}$ Sobre estas cuestiones puede verse el trabajo de Consolación Baranda, "De "Celestinas»: Problemas metodológicos," Celestinesca 16.2 (1992): 3-32. 
Melibea, y por el nombre de la alcahueta se cita en licencias, tasas y aprobaciones ${ }^{33} \mathrm{e}$ incluso así es citada en la relación de bienes del regidor de Santiago, Francisco de Treviño. ${ }^{34}$ Es decir, estamos una vez más ante un claro mecanismo de relación cíclica, pero al mismo tiempo ante la consideración de Hurtado, como antes había ocurrido con la Tragicomedia de Calisto y Melibea, de que el personaje esencial era la tercera y no los enamorados.

En cuanto a las correcciones ortográficas que realiza Hurtado éstas se distribuyen en dos ámbitos. Por un lado trata de solventar las erratas que se han deslizado en la editio princeps, lo que no es óbice para que en la suya aparezcan otras. En este aspecto su intervención carece de todo interés y se ajusta al trabajo convencional de un corrector, ya que, no siendo habitual que los autores se encarguen de la corrección, es el corrector de imprenta quien desarrolla esta actividad. ${ }^{35}$ Por otro lado nos encontramos con un amplio aparato de variantes estrictamente lingüisticas. Respecto a este punto, conviene recordar que el siglo XVI presenta "un idioma en evolución muy activa"36 que progresivamente. va intentando finiquitar las vacilaciones de timbre en las vocales, simplificar los grupos consonánticos, transformar las consonantes, etc.; en definitiva, se trataba de fijar el ideal lingüístico, que no es otro que el de Juan Valdés.

Obviamente, la aparición de la imprenta, que supuso un cambio radical en el entramado de relaciones entre los distintos actores del libro $^{37}$ y a la que Suárez de Figueroa considera "madre de las honras deuidas a sujetos famosos, centro de ingenios sutiles, perpetuo albergue de Senadores, Teologos, Filosofos, Historicos, Academicos, Doctores,

${ }^{33}$ Erna Berndt-Kelley, "Peripecias de un título," Celestinesca 9.2 (1985): 3-45.

${ }^{34}$ Steven D. Kirby, "¿Cuándo empezó a conocerse la obra de Fernando de Rojas como Celestina?," Celestincsca 13.1 (mayo 1989): 59-60.

${ }^{35}$ J. Moll, "Problemas bibliogríficos del libro del Siglo de Oro," Boletin de la Real Academia Española 59 (1979), p. 94.

${ }^{36}$ R. Lapesa, Historia de la lcngua española (Madrid: Gredos, 1980 ), p. 367.

37 V. Infantes, "1492: una cultura entre el libro y el lector," en Gramática y Humanismo. Perspectivas del Renacimiento, ed. Pedro Ruiz Pérez (Córdobn: Ayuntamiento de Córdoba/Ediciones Libertarias, 1993), p. 61. 
Estudiantes, y de todo lo bueno y loable que se halla en la ciudad,"38 contribuyó también a la paulatina regularización del idioma, pero al mismo tiempo hizo que los distintos impresores, y por lo tanto los distintos correctores, aplicasen sus propios criterios sobre los textos. ${ }^{39}$

De acuerdo con esto, lo que nos encontramos en la segunda edición de la Tragedia Policiana es un claro ejemplo de ese momento de confusión ortográfica que vive el idioma, de manera que si bien en las piezas preliminares y en el primer acto parece observarse una actitud de Luis Hurtado que tiende a ofrecer las soluciones ortográficas más modernas, pronto nos encontramos con las mismas arbitrariedades y vacilaciones aparecidas en la primera edición, de modo que, por ejemplo, en unos casos la lección de Hurtado ofrece la grafía -s- en lugar de -sspara acto seguido corregir el original en sentido contrario. Así pues, no estamos ante dos sistemas ortográficos distintos y coherentes en sí mismos, sino simplemente ante la ejemplificación clara de las fluctuaciones lingüísticas de la época, donde cada redactor aplica sus propios gustos.

Respecto a las supresiones y adiciones, es donde el papel de corrector de Luis Hurtado se manifiesta en su sentido más amplio, lo que da como resultado un amplio cuerpo de variantes detallado en mi edición. ${ }^{40}$ Las supresiones afectan fundamentalmente a palabras de poca entidad gráfica como conjunciones, artículos o pronombres (haplografia). En general, estas supresiones no suponen ninguna alteración sustancial del texto original, ${ }^{41}$ pero sí manifiestan una clara voluntad estilística. Por otro lado, son pocas las ocasiones en que se produce la supresión de un párrafo completo (omissio ex homoioteleuto) como ocurre con la supresión

38 Cristóbal Suárez de Figueroa, Plaza unizersal de todas las ciencias y artes (Madrid, 1616) fo. $336 r$ y $v$.

${ }^{39}$ Blecua, 140-141.

${ }^{40}$ Luis Mariano Esteban Martín, "Edición y Estudio de la Tragedia Policianta, de Sebastián Fernández" (Tesis, Universidad Complutense de Madrid [colección Tesis Doctorales n0388/92],1992], pp. 34()-352. Pari las citas de la Tragctia Policiana sigo esta edición.

11 En este sentido habría que exceptuar la supresión de $n$ en las siguientes palabras de Palermo a Piçarro:"Pero no me paresce mal que andemos sobre el aviso..." (VII,141), ya que se cambia completamente el sentido de sus palabras, lo que, en mi opinión, es fruto de una errata. 
de un breve diálogo entre Polidoro y Machorro ante la llegada de Philomena:

Polidoro: -Ea pues, átame, si ha gana, que está hombre parado por atendella.

Machorro: -Prissa, prissa, que ella se llegará si pluguiere. (XXI,pág. 228)

En cualquier caso, la supresión del mismo no tiene especial importancia y es probable que se deba a una errata más que a una intención expresa de supresión.

En cuanto a las adiciones, muy numerosas, se distribuyen a lo largo de la obra sin que Luis Hurtado manifieste una predilección por los parlamentos de algún personaje. En general, estas adiciones se limitan a intensificar lo expresado en la editio princeps en ocasiones con una finalidad estilística y siempre con un claro prurito de intervenir en obra ajena de acuerdo con lo que era, como hemos visto, el papel habitual de los correctores, y en especial del corrector Luis Hurtado de Toledo.

En conclusión, no me parece que pueda mantenerse duda alguna sobre que Luis Hurtado de Toledo no es el autor de la Tragedia Policiana, sino que estamos ante un corrector de imprenta que, como era usual en la época, realiza una serie de variaciones - numerosas, por otra parte sobre la primera edición de la obra e incluso añade unas octavas finales con las que, además de cumplir una de las actividades más frecuentes de su creación literaria, reafirma, como un mecanismo más de relación, la vinculación del texto de Sebastián Fernández con el ciclo celestinesco. ${ }^{42}$

${ }^{42}$ Terminado este artículo, me ha llegado el trabajo de Sagrario López Poza, "Las Trescientas de Luys Hurtado, manuscrito de la Biblioteca de la Universidad de Santiago," Salina. Revista de LLetres 7 (1993): 49-55, donde se describe este manuscrito del siglo XVI, que contiene seis obras cuya edición promete la autora. 